\title{
MEASUREMENT OF THE BLOOD FLOW VELOCITY IN THE PERICALLOSAL ARTERY OF CHILDREN WITH HYDROCEPHALUS BY TRANSCRANIAL DOPPLER ULTRASONOGRAPHY - PRELIMINARY RESULTS
}

\author{
Julius De Riggo ${ }^{a *}$, Branislav Kolarovszki ${ }^{\mathrm{a}}$, Romana Richterova ${ }^{\mathrm{a}}$, Hana Kolarovszka ${ }^{\mathrm{b}}$, \\ Juraj Sutovsky ${ }^{\mathrm{a}}$, Peter Durdik ${ }^{\mathrm{c}}$
}

\author{
a Clinic of Neurosurgery, Jessenius Faculty of Medicine, Comenius University, Kollarova 2, 03601 Martin, Slovak \\ Republic \\ b Clinic of Neonatology, Jessenius Faculty of Medicine, Comenius University, Martin \\ c Clinic of Children and Adolescents, Jessenius Faculty of Medicine, Comenius University, Martin \\ e-mail:deriggo@mfn.sk
}

Received: August 15, 2007; Accepted: September 20, 2007

Key words: Pediatric hydrocephalus/Transcranial Doppler ultrasonography/Brain circulation

Aim: The goal of this study was to evaluate selected parameters of the Doppler curve of the pericallosal artery at children with hydrocephalus.

Methods: 12 patients with hydrocephalus were divided into two groups. Group 1 comprised children needing cerebrospinal fluid drainage, and group 2 comprised children without any indication for drainage or with an already inserted well-functioning drainage system. Dilatation of the cerebral ventricles was determined by transcranial ultrasonography. Following parameters of a blood flow of the pericallosal branch of the anterior cerebral artery: peak systolic blood flow velocity (PSFV), end-diastolic blood flow velocity (EDFV) and resistive index (RI) were observed by transcranial Doppler ultrasonography. Parameters of The Doppler curve were measured without pressure (baseline parameters) and during compression of the anterior fontanelle (pressure provocation test).

Results: Group 1: baseline parameters: PSFV $68.9 \pm 13.52 \mathrm{~cm} / \mathrm{s}$, EDFV $18.26 \pm 10.39 \mathrm{~cm} / \mathrm{s}$, RI $0.76 \pm 0.12$; parameters during pressure provocation test: PSFV $66.92 \pm 19.75 \mathrm{~cm} / \mathrm{s}$, EDFV $10.88 \pm 11.18 \mathrm{~cm} / \mathrm{s}$, RI $0.86 \pm 0.14$. Group 2 : baseline parameters: PSFV $59.95 \pm 19.38 \mathrm{~cm} / \mathrm{s}$, EDFV $20.65 \pm 8 \mathrm{~cm} / \mathrm{s}$, RI $0.65 \pm 0.04$; parameters during the pressure provocation test: PSFV $57.14 \pm 18.91 \mathrm{~cm} / \mathrm{s}$, EDFV $17.7 \pm 8.3 \mathrm{~cm} / \mathrm{s}$, RI $0.68 \pm 0.05$

Conclusion: The results show increased baseline and postcompressive values of RI of pericallosal artery in infants with hydrocephalus before drainage procedure and normal values of RI at children without the need for cerebrospinal fluid drainage or with a well-functioning drainage system.

\section{INTRODUCTION}

Hydrocephalus is characterised by an excessive accumulation of cerebrospinal fluid, as a result of failure in production, flow or absorption of CSF. It may be congenital or acquired.

The CSF accumulation is nearly always accompanied by ventricular enlargement. Elevation an intracranial pressure is in most cases present. Principally it occurs as a hydrodynamic disorder of cerebrospinal fluid. An exception is so-called "arrested hydrocephalus" which leaks the progressive dilatation of brain ventricles and the negative consequences of hydrocephalus. There is a normal growth curve of head circumference. Stabilisation of a ventricles size is due to alternative pathways of CSF absorption. Lots of factors might disrupt this fragile intracranial equilibrium and induce acute elevation of ICP with hydrocephalus decompensation (infection, fever, mild injury, etc.). Another exception is hydrocephalus ex vacuo, when dilatation of ventricles is caused by atrophy of a brain tissue. There is no increase in ICP.
Pathophysiological changes in progressive pediatric hydrocephalus include: increased intracranial volume, progressive dilatation of ventricles, decreased intracranial compliance, increased intracranial pressure, alteration in brain circulation and secondary brain impairment, such as a hypoperfusion, ischaemia, alteration in metabolism (acidosis, higher lactate concentration, etc.), changes in neurotransmitters, damage to associative pathways, cortex and white matter. Periventricular axons and myelin are primary targets of the injury. Secondary changes in neurons reflect the stress or ultimately the disconnection of axons ${ }^{1}$.

Transcranial Doppler colour coded sonography is noninvasive and a relatively new method that combines imaging of cerebral blood vessels and a brain tissue with the examination intracranial hemodynamics at patient's bedside. It may be used for various indications. The most common clinical applications are: evaluation of the cerebrovascular status in stroke patients, diagnosis of cerebral vasospasm, detection of aneurysms and arteriovenous malformations, indirect detection of cerebral 
venous thrombosis, monitoring space-occupying brain oedema, that may lead to herniation of brain tissue, intracerebral hemorrhage, mainly in a supratentorial location, intracranial hypertension, hydrocephalus, brain tumors and neurodegenerative diseases, such as Parkinson's or the Huntington's disease ${ }^{2-6}$.

Symptoms of hydrocephalus vary with age, disease progression and individual tolerance to changes in CSF volume. In infancy, the most common clinical signs are: discomfort, lethargy, irritability, drowsiness, increasing head circumference, macrocrania, bulging fontanelle, distension of scalp veins, suture diastasis, swelling of optic disc, downward deviation of the eyes (called "sunsetting" sign), nausea, vomiting, bradycardia, episodes of apnea, recurrent aspiration, respiratory arrest, poor feeding and sucking, problems with balance, poor coordination, slowing or loss of development. However, clinical signs of raised ICP are known to be unreliable and sometimes even misleading.

The aim of this prospective study was to evaluate selected parameters of the Doppler curve of pericallosal artery in children with hydrocephalus to decide whether drainage procedure is needed and to monitor the function of already inserted drainage systems.

\section{MATERIALS AND METHODS}

In our study we focused on evaluation of the brain circulation in children with hydrocephalus by means of transcranial colour coded Doppler sonography.

The patients were divided into two groups. The group 1 comprised 6 patients ( 5 boys and 1 girl) with an average age of 215 days. Included were patients before drainage procedure into this group. The aetiology of hydrocephalus in this group was as follows: congenital $(n=5)$, posthaemorrhagic $(n=1)$ and postinfectious $(n=2)$. In some cases the aetiology was combined. The type of hydrocephalus: three ventricles dilatation $(n=4)$, four ventricles dilatation $(n=1)$, cystic schizencephaly $(n=1)$. Surgical treatment included: insertion of ventriculo-peritoneal shunt $(n=3)$, endoscopic ventriculostomy $(n=2)$ and a revision of malfunctioning ventriculo-peritoneal shunt $(n=1)$. Group 2 consisted of 6 patients ( 5 boys and 1 girl) with an average age 246 days. This group comprised patients without the need for CSF drainage or with an already inserted functioning drainage system. The aetiology of hydrocephalus in this group was as follows: congenital $(n=5)$, posthaemorrhagic $(n=1)$ and postinfectious $(n=2)$. In some cases the aetiology was combined. The type of hydrocephalus: three ventricles dilatation $(n=4)$, four ventricles dilatation $(n=2)$. The surgical treatment: no need for CSF drainage $(n=4)$, a well-functioning ventriculo-peritoneal shunt without the need for shunt revision $(n=2)$.

All patients underwent the ground neurological evaluation where clinical signs of intracranial hypertension were observed. The other part of examination was an ultrasonographical morphometry of a brain (width of cerebral ventricles). The transcranial colour coded Doppler sonography was used for assessment of haemodynamic param- eters of brain circulation using the anterior fontanelle as an acoustic window. TCCD was performed on the device ALOKA with $5 \mathrm{MHz}$ transducer. Parameters were examined from the pericallosal branch on the anterior cerebral artery, in its vertical course anterior to the genu corporis callosi. The examination was performed with light contact of transducer on the anterior fontanelle (baseline parameters) and with its compression (pressure provocation test). The following parameters were measured: peak systolic flow velocity (PSFV), end-diastolic flow velocity (EDFV) and resistive index (RI, Pourcelot index), that is obtained by dividing the difference between the peak systolic flow velocity and end-diastolic flow velocity by peak systolic flow velocity: RI = $($ PSFV - EDFV $) /$ PSFV. All parameters were measured both, with only light contact of transducer with anterior fontanelle and during compression of fontanelle - pressure provocation test.

Extracranial factors that might affect shape and characteristics of Doppler curve were assessed, such as: body temperature, haematocrit, haemoglobin, blood gases, condition of the child during examination, presence of congenital developmental defects of heart and major blood vessels.

Informed consent from all mothers of investigated newborns and children was obtained. The study protocol was approved by the Ethics Committee of the Jessenius Faculty of Medicine, Comenius University in Martin, Slovakia.

\section{RESULTS}

Through the use of ultrasonography we collected and compared results in both groups. One pursued parameter was width of cerebral ventricles - both lateral and third ventricle. There are obviously bigger width parameters in the group 1 (Table 1).

Other compared parameters acquired through the use of TCCD were parameters of the Doppler curve of pericallosal artery in both groups. The measurement was performed without any pressure (baseline parameters) and during compression of the anterior fontanelle (pressure provocation test). PSFV was higher in the group 1 and did not change after fontanelle compression. EDFV was decreased in the group 1 in comparison with group 2 where EDFV had normal values. RI was higher in the group 1 and this increase was move pronounced after fontanelle compression. There was no change in the group 2 in RI after compression of the anterior fontanelle (Table 2, Graph 1, Figgure 1).

\section{DISCUSSION}

The transcranial colour coded Doppler sonography provides a bedside noninvasive and easily repeatable means of monitoring cerebrohaemodynamic changes with good clinical applications.

The outcomes of clinical and experimental studies show a correlation between increase in ICP and changes 


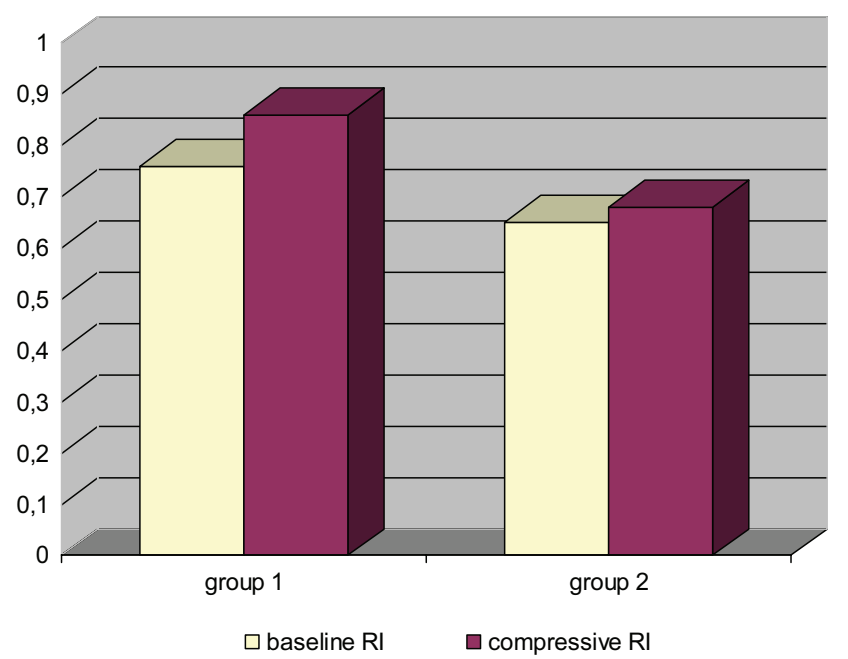

Graph 1. Comparison of resistive index (RI) of Doppler curve of the pericallosal artery between the group 1 and the group $2(\mathrm{n}=12)$

in Doppler curve: mainly decreased end-diastolic velocity of cerebral blood flow and increased RI. The mean cerebral blood flow is mainly determined from the diastolic flow. As ICP rises, the arterial flow is more affected during the diastole than during the systole, resulting in an increase in $\mathrm{RI}^{7}$. The results of a study published by Taylor (1996) show that the change in RI during fontanelle compression is a better predictor of ICP than is the RI value obtained without the fontanelle compression, and that this technique can be used to monitor the effectiveness of surgical therapies in children with hydrocephalus ${ }^{8}$.

The relationship between ICP and haemodynamic parameters of brain vessels on the Doppler curve, notably the RI, is of a complex nature and is therefore expected to be nonlinear. In addition, many factors, apart from ICP may influence the RI of right intracranial vasculature, such as an age, physical and mental activity, manipulation and examination of the patient, body temperature, metabolic activity, functionality of brain autoregulation, $\mathrm{PaO} 2, \mathrm{PaCO} 2, \mathrm{pH}$, morphological changes in vessels and brain tissue, cardiac output, heart rate, cerebral vascular resistance, the presence of patent ductus arteriosus, cerebral perfusion pressure, blood viscosity, systemic blood pressure, use of vasoactive medications?

In pediatric hydrocephalus, the rationale for indication of CSF drainage is currently progression of ventricular enlargement on consecutive imaging studies and the presence of clinical signs of increased ICP. The mere presence of ventriculomegaly on ultrasonography, CT or MRI cannot be used as an indication for treatment. When ICP values are normal or only minimally elevated, the risks of drainage (shunt infection, slit ventricle syndrome, subdural hygromas, and further distortion of brain architecture) do not outweigh the benefits, and drainage is therefore contraindicated ${ }^{10}$. On the other hand, early obstruction of CSF flow, initially may not lead to ventricular dilatation, yet may distort the brain architecture and compromise cerebral perfusion to such an extent brain damage ensues.
Table 1. A comparison of the width of cerebral ventricles between the group 1 and the group $2(n=12)$

\begin{tabular}{|l|c|c|}
\hline & Group 1 & Group 2 \\
\hline $\begin{array}{l}\text { Left lateral } \\
\text { ventricle }(\mathrm{cm})\end{array}$ & $4.08 \pm 1.94$ & $2.10 \pm 1.94$ \\
\hline $\begin{array}{l}\text { Right lateral } \\
\text { ventricle }(\mathrm{cm})\end{array}$ & $4.03 \pm 1.91$ & $2.12 \pm 1.54$ \\
\hline $\begin{array}{l}\text { Third ventricle } \\
(\mathrm{cm})\end{array}$ & $2.10 \pm 0.96$ & $0.70 \pm 0.20$ \\
\hline
\end{tabular}

Table 2. A comparison of the parameters of the Doppler curve of the pericallosal artery between the group 1 and the group $2(\mathrm{n}=12)$

\begin{tabular}{|l|c|c|}
\hline & Group 1 & Group 2 \\
\hline Baseline parameters & & \\
\hline PSFV (cm/s) & $68.90 \pm 13.52$ & $59.95 \pm 19.38$ \\
\hline EDFV (cm/s) & $18.26 \pm 10.39$ & $20.65 \pm 8.00$ \\
\hline RI & $0.76 \pm 0.12$ & $0.65 \pm 0.04$ \\
\hline $\begin{array}{l}\text { Pressure } \\
\text { provocation test }\end{array}$ & $66.92 \pm 19.75$ & $57.14 \pm 18.91$ \\
\hline PSFV (cm/s) & $10.88 \pm 11.18 *$ & $17.70 \pm 8.30$ \\
\hline EDFV (cm/s) & $0.86 \pm 0.14$ & $0.68 \pm 0.05$ \\
\hline RI & & \\
\hline
\end{tabular}

PSFV - peak systolic flow velocity, EDFV - end-diastolic flow velocity, RI - resistive index

* Discrepancy greater than the average is caused by the children With EDFV $=0$ included in the observed group.

The ventricular dilatation without significant rise in ICP may indicate the presence of a new equilibrium between CSF production and resorption (arrested hydrocephalus), and these children probably do not benefit from the drainage procedure. 
1a - baseline parameters

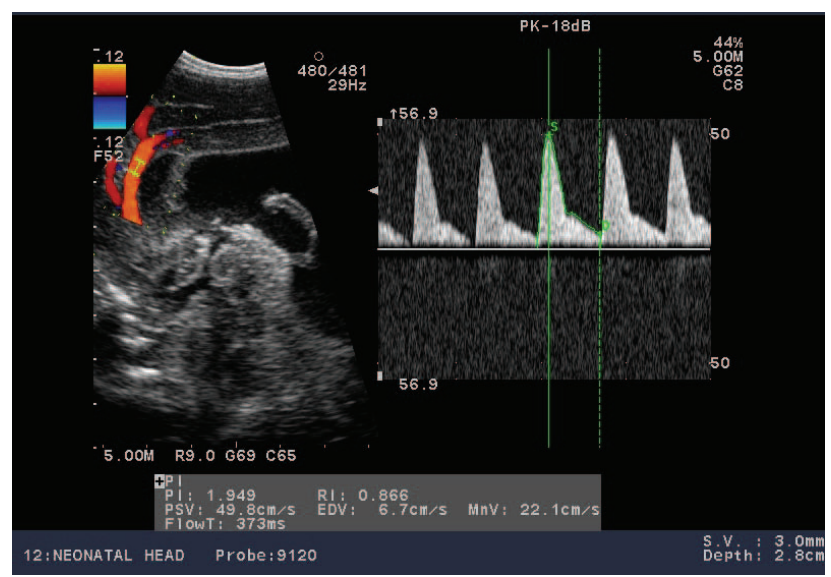

$1 \mathrm{~b}$ - anterior fontanelle pressure provocation test

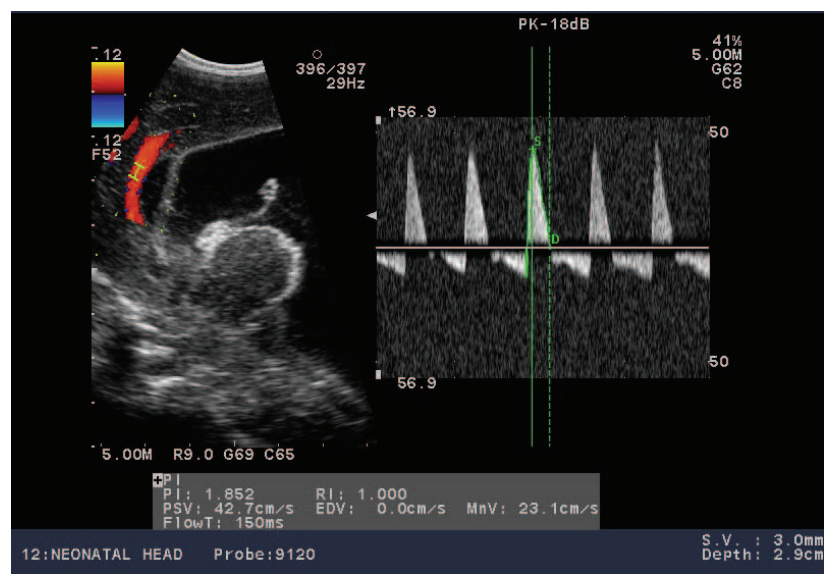

Fig. 1. Doppler curve of the pericallosal artery in the infant with progressive three-ventricular hydrocephalus before drainage procedure: $1 \mathrm{a}$ - baseline parameters, $1 \mathrm{~b}$ - anterior fontanelle pressure provocation test

Parameters of the Doppler curve of the pericallosal artery serve as indication criteria for drainage intervention in children with hydrocephalus as well as good timing predictor for intervention ${ }^{11}$. Another application is in detection of functional disturbance of already inserted drainage system. Early diagnosis allows a proper indication for surgery initially or after development of complications in patients with malfunctioning shunts, thus reducing the chance deterioration cognitive functions ${ }^{12}$.

It is most likely that the increase in blood flow velocity reflects an increase in cerebral blood flow in response to reduction in intracranial pressure after CSF drainage. Mean CSF pressure, which is likely to be the same as intracranial pressure, is lower after the drainage procedure $^{13}$.

The lack of specificity of symptoms of shunt blockage has resulted in a greater reliance on the examination and investigation. Palpation or pumping chamber of valve is unreliable. The brain CT shows enlarged ventricles but a previous scan is required for comparison ${ }^{14}$.

Symptoms of malfunctioning CSF shunt may be easily confused with those of intercurrent illness: headache, vomiting and drowsiness are presenting features of a multitude of childhood illnesses. In patients with malfunctioning shunts changes in Doppler curve of cerebral arteries (increase RI due to decrease in EDFV) are present much earlier than progression dilatation of brain ventricles ${ }^{15}$.

The introduction of pressure provocation test of anterior fontanelle to examine CSF storage capacity has lead to greater accuracy of TCCD ultrasonography to separate normal from (borderline) abnormal values ${ }^{16}$. Initially, a change in intracranial volume is offset with volume shifts in other components so that ICP remains essentially unchanged. As the capacity to shift volume is surpassed, further increases in intracranial volume result in elevation of ICP. During graded fontanelle compression in normal infants, cerebrospinal fluid or a blood can be readily displaced to compensate for the small increase in the volume delivered by the transducer, which results in no increase in ICP. In infants with an abnormal intracranial compliance, however, the increase in intracranial volume with the graded fontanelle compression is translated into a transient increase in ICP and a concomitant decrease in cerebral perfusion pressure ${ }^{17}$. The increase in ICP manifests as increased RI and the decrease in end-diastolic flow velocity, sometimes even mild decrease in peak systolic blood flow velocity and also the reversed diastolic blood flow. ICP is measured indirectly by changes in RI and EDFV as presented also in our study.

\section{CONCLUSIONS}

The results of our study show that in children with hydrocephalus before the insertion of the CSF drainage, there is alteration in brain circulation. This can be verified by means of TCCD examination. There are changes on baseline and postcompressive haemodynamic parameters of the Doppler curve of the pericallosal artery, mainly increase in RI and decrease in EDFV.

Transcranial colour-coded Doppler ultrasonography can be used to monitor children with hydrocephalus. It is a useful, noninvasive predictor of elevated ICP and decreased intracranial compliance. It is helpful in the indication and the timing of CSF drainage procedure or predicting the need for a revision operation in malfunctioning shunts. Transcranial colour-coded Doppler ultrasonography currently plays an important role in the surgical decision making in patients referred for CSF drainage procedures. In spite of the common use of various imaging techniques, physical examination remains an inseparable part of the assessment of intracranial dynamics in children with hydrocephalus. Parents who are able to observe subtle changes in the behavior of their child play an important role. 


\section{ABBREVIATIONS}

CSF - cerebrospinal fluid, ICP - intracranial pressure, TCCD - transcranial Doppler colour coded sonography, PSFV - peak systolic flow velocity, EDFV - end-diastolic flow velocity, RI - resistive index, CT - computed tomography, MRI - magnetic resonance imaging

\section{ACKNOWLEDGEMENTS}

The study was supported by Grant VEGA 1/4249/07

\section{REFERENCES}

1. Del Bigio MR. Cellular damage and prevention in childhood hydrocephalus. Brain Pathol 2004; 14:317-24.

2. Krcho, P. Ultrazvukové vyšetrenie mozgu novorodenca. In: Zibolen M, Zbojan J, Dluholucký S, et al. Praktická neonatológia. Martin: Vydavatel'stvo Neografie; 2001. p. 201-5.

3. Krcho P. Ultrazvukové vyšetrenie mozgu novorodenca. Lek Obz 2005; 54:508-11.

4. Matašová K, Čiljak M, Murgaš D, Zibolen M. Arteriovenózna malformácia mozgu novorodenca. Neonatologické zvesti 2003; 7:19-20.

5. Minárik M, Strechová Z, Hlaučová E, Matašová K. Rýchlosṫ prietoku krvi mozgom zdravého novorodenca v prvých dňoch života. Čes.-slov. Pediat. 1993; 48:530-4.

6. Zipper GS, Stolz E. Clinical application of transcranial colour-coded duplex sonography - a review. European Journal of Neurology 2002; 9:1-8.

7. Maertzdorf WJ, Vles JSH, Beuls E, Mulder ALM, Blanco CE. Intracranial pressure and cerebral blood flow velocity in preterm infants with posthaemorrhagic ventricular dilatation. Arch Dis Child Fetal Neonatal Ed 2002; 87:185-8

8. Taylor GA, Madsen JR. Neonatal Hydrocephalus: Hemodynamic Response to Fontanelle Compression- Correlation with Intracranial Pressure and Need for Shunt Placement. Radiology 1996; 201:685-9.

9. Minárik M. Niektoré otázniky pri transkraniálnej Dopplerovej sonografii u kriticky chorých detí. Čes.-slov. Pediat. 1999; 54:697-9.

10. Gera P, Gupta R, Sailukar M, Pathak R, Agarwal P, Parelkar S, et al. Role of Transcranial Doppler Sonography and Pressure Provocation Test to Evaluate the Need for Cerebrospinal Fluid Drainage in Hydrocephalic Children. J Indian Assoc Pediatr Surg 2002; 7:174-83.

11. Goh D, Minns RA, Pye SD. Transcranial Doppler (TCD) Ultrasound as a Noninvasive Means of Monitoring Cerebrohaemodynamic Change in Hydrocephalus. Eur J Pediatr Surg 1991; Suppl 1:14-7.

12. De Oliveira RS, Machado HR. Transcranial color-coded Doppler ultrasonography for evaluation of children with hydrocephalus. Neurosurg Focus 2003, 15

13. Kempley ST, Gamsu HR. Changes in cerebral artery blood flow velocity after intermittent cerebrospinal fluid drainage. Arch Dis Child 1993; 69:74-6

14. Jindal A, Mahapatra AK. Correlation of ventricular size and transcranial Doppler findings before and after ventricular peritoneal shunt in patients with hydrocephalus: prospective study of 35 patients. J Neurol Neurosurg Psychiatry 1998; 65:269-71.

15. Quinn MW, Pople IK. Middle cerebral artery pulsatility in children with blocked cerebrospinal fluid shunts. J Neurol Neurosurg Psychiatry 1992; 55:325-7.

16. Westra SJ, Lazareff J, Curran JG, Sayre JW, Kawamoto JrH. Transcranial Doppler Ultrasonography to Evaluate Need for Cerebrospinal Fluid Drainage in Hydrocephalic Children. J Ultrasound Med 1998; 17:561-9.

17. Taylor GA, Phillips MD, Ichord RN, Carson BS, Gates JA, James CS. Intracranial Compliance in Infants: Evaluation with Doppler US. Radiology 1994; 191:787-791. 